\title{
URGENSI KEARIFAN LOKAL MELALUI MUSIK GAMELAN DALAM KONTEKS PENDIDIKAN SENI DI ERA 4.0
}

\section{THE URGENCY OF LOCAL WISDOM THROUGH GAMELAN MUSIC IN THE CONTEXT OF ART EDUCATION IN ERA 4.0}

\author{
Alfa Kristanto ${ }^{1}$ \\ ${ }^{1}$ Sekolah Tinggi Theologia Abdiel, Ungaran \\ ${ }^{(*)}$ (e-mail) alfaomega.kristanto@gmail.com
}

\begin{abstract}
Abstrak
Musik merupakan hasil dari pemikiran dan proses kreatif. Karya musik diciptakan melalui ide-ide baru kepada penikmatnya. Dalam konteks pendidikan musik, kreativitas merupakan alat untuk mencapai tujuan pembelajaran musik. Strategi pembelajaran didasaran pada pemikiran untuk memancing peserta didik menumbuhkan ide-ide (divergen) dan mencari solusi (konvergen). Artikel ini mempersepsikan kreativitas sebagai sebuah alat berpikir dalam konteks pendidikan musik. Literature review digunakan sebagai metode untuk melakukan identifikasi mendalam dan kritis terhadap penelitian sebelumnya (Aveyard, 2014). Kreativitas memberikan nilai pada kualitas pembelajaran musik melalui aktivitas berpikir yang dinamis. Mengaransemen, berimprovisasi dalam materi musik tertentu (seperti jazz), dan secara teratur mempraktikkan sight-reading adalah pola belajar yang berlandaskan kreativitas. Musik dapat dilibatkan dalam proses pembelajaran untuk membangkitkan gairah dalam belajar musik (lihat: Ritter \& Ferguson, 2017).
\end{abstract}

Kata kunci: Kreativitas, pendidikan musik, berpikir divergen dan konvergen

\begin{abstract}
Music derives from thinking and creative processes. It creates music works through fresh ideas to the audience. In music school, creativity is a medium to accomplish the objective of music learning. Learning methods based on logic were to encourage pupils to spread ideas (divergent) and get explanations (convergent). This article perceives creativity as a medium for thinking in music education. I employed a Literature review as a method for in-depth and critical description of early investigation (Aveyard, 2014). Creativity allows value to the capacity of music learning through effective thinking works. Arranging, improvising in specific musical object (such as jazz), and commonly practicing sightreading are learning standards based on creativity. They can involve music in the learning process to arouse excitement for learning music (see: Ritter \& Ferguson, 2017).
\end{abstract}

Keywords: Creativity, music education, divergent and convergent thinking

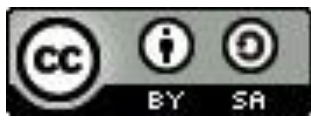




\section{Pendahuluan}

Modernisasi sebagai bentuk perkembangan zaman yang bersifat dinamis dan progresif ditengah-tengah masyarakat dewasa ini turut mempengaruhi perkembangan berbagai aspek kehidupan manusia. Menurut (Gorontalo, Pratiknjo, 2015) menjelaskan bahwa modernisasi adalah suatu proses transformasi dari suatu arah perubahan ke arah yang lebih maju atau meningkat dalam berbagai aspek kehidupan masyarakat. Dijelaskan lebih lanjut oleh (Robet, 2016) bahwa sebagai gejala, modernitas secara historis merujuk pada munculnya suatu bentuk masyarakat di Eropa pada sekitar abad 17 dan 18 yang dibimbing oleh ideal-ideal pencerahan mengenai rasionalitas, progresifitas. Dirayakan sebagai abad baru bagi umat manusia yang salah satunya ditandai oleh ilmu pengetahuan, teknologi, inovasi, dan teknologisasi berbagai bidang kehidupan.

Menurut (Lase, 2019), saat ini dunia telah memasuki era revolusi industri generasi 4.0 yang ditandai dengan meningkatnya konektivitas, interaksi serta perkembangan sistem digital, kecerdasan artifisial, dan virtual. Dengan semakin konvergennya batas antara manusia, mesin dan sumber daya lainnya, teknologi informasi dan komunikasi tentu berimbas pula pada berbagai sektor kehidupan. Salah satunya yakni berdampak terhadap sistem pendidikan di Indonesia. Perubahan era ini tidak dapat dihindari oleh siapapun sehingga dibutuhkan penyiapan sumber daya manusia (SDM) yang memadai agar siap menyesuaikan dan mampu bersaing dalam skala global. Peningkatan kualitas SDM melalui jalur pendidikan mulai dari pendidikan dasar dan menengah hingga ke perguruan tinggi adalah kunci untuk mampu mengikuti perkembangan Revolusi Industri 4.0. Menurut (Sabri, Jazuli, F, \& Abdillah, 2019) istilah Revolusi Industri 4.0 pertama kali diperkenalkan oleh Profesor Klaus Schwab. Seorang ekonom terkenal asal Jerman yang menulis dalam bukunya: The Fourth Industrial Revolution. Sebenarnya beberapa negara juga mempunyai roadmap digitalisasi industri yang serupa. Seperti, China dengan Made in China 2025, Asia dengan Smart Cities. Dan Kementerian Perindustrian juga mengenalkan Making Indonesia 4.0, yang pada bulan April 2018 dicanangkan oleh Presiden Joko Widodo.

Dinamika perkembangan zaman mempengaruhi perilaku seseorang sebagai makhluk berbudaya. Di era revolusi industri 4.0 berdampak pada berjejalnya informasi-informasi yang bersifat cepat. Informasi dalam hal ini dapat diartikan sebagai bentuk sajian data yang mampu menjawab kebutuhan manusia yang bisa didapatkan dengan waktu yang singkat. Semangat praksis individual lebih mendominasi di era revolusi industry 4.0 ini, karena dengan cepat seseorang bisa mencari informasi yang sudah termuat dalam media sosialisasi dengan bentuk yang beragam. Generasi yang hidup di era revolusi industri 4.0 akan mendukung situasi tersebut, tetapi perlu direnungkan terkait pentingnya mempertahankan penanaman nilainilai kebersamaan seiring perkembangan zaman. Mengamati pemaparan diatas, perlu adanya upaya menyeimbangkan antara manusia sebagai makhluk individu dan makhluk sosial atau makhluk yang berbudaya. Manusia adalah makhluk budaya yang selalu terikat oleh nilai-nilai kebudayaan yang terkandung di dalamnya.

Kebudayaan di Indonesia memiliki nilai-nilai yang berbeda yang tercermin dari kesenian yang terdapat pada suatu daerah tertentu, karena seni lahir dari latar belakang kehidupan sosial-budaya penciptanya (seniman) yang didalamnya memiliki nilai estetika tersendiri. Menurut Koentjaranigrat (1990: 203) menyatakan unsur-unsur universal dari setiap kebudayaan meliputi: (1) Bahasa, (2) Sistem Pengetahuan, (3) Organisasi Sosial, (4) Sistem Peralatan Hidup, (5) Sistem Mata Pencaharian Hidup, (6) Sistem Religi, dan (7) Kesenian. Hasil 
kesenian seperti musik yang memiliki wujud dan karakteristik berbeda-beda dari setiap daerah atau pulau-pulau yang ada di Indonesia merupakan bentuk dari keberagaman kebudayaan Indonesia. Kebudayaan seni tradisional di era modern ini terlihat bahwa masyarakat mulai mengabaikan kebudayaan bangsanya sendiri.

Seni tradisional merupakan kebudayaan yang patut dan penting untuk mendapatkan perhatian karena kebudayaan merupakan identitas dari suatu bangsa. Kebudayaan sangat erat hubungannya dengan masyarakat, seperti yang dijelaskan Danandjaja dalam (Darma, 2011) bahwa nilai-nilai tradisi masyarakat terwujud dalam berbagai bentuk, di antaranya cerita-cerita lisan yang merupakan bagian dari folklor dan menjadi sebuah warisan budaya. Kesenian tradisional yang sarat dengan nilai-nilai budaya seyogyanya dapat menjadi sarana pewarisan bagi generasi penerus bahkan menjadi identitas suatu daerah, dikarenakan seni sebagai produk budaya mampu merefleksikan ekspresi simbolik suatu budaya masyarakat tertentu (Murni, Rohidi, 2016).

Kesenian tradisional di Indonesia yang sangat beragam ini menunjukkan bahwa Indonesia adalah bangsa yang kaya dengan nilai-nilai kearifal lokal di bidang seni. Menurut ( $T$ Triyanto, 2009) kearifan lokal sebagai bentuk budaya diyakini memiliki nilai sejati dan membawa kebaikan di daerah setempat, keberadaannya harus dipertahankan. Kearifan Lokal terdiri dari 2 kata yaitu kearifan (wisdom) dan lokal (local). Local berarti setempat dan wisdom sama dengan kebijaksanaan. Dengan kata lain maka kearifan lokal (local wisdom) dapat dipahami sebagai gagasan-gagasan, nilai- nilai-nilai, pandangan-pandangan setempat (local) yang bersifat bijaksana, penuh kearifan, bernilai baik, yang tertanam dan diikuti oleh anggota masyarakatnya (Antosa, 2014, p. 86). Salah satu contoh bentuk kearifan lokal yang dimiliki Indonesia yaitu kesenian/musik gamelan Jawa.

Menurut Suwaji Bastomi $(1992,113)$ Gamelan adalah permainan musik jawa yang bagian-bagiannya berupa alat perkusi yang dibuat dari perunggu atau "gangsa". Gangsa berasal dari kata Gasa artinya perbandingan antara timah : tembaga adalah 3 (tiga) : 10 (sedasa). Namun ada pula gamelan yang dibuat dari besi. Pemainnya disebut "pradangga", penyanyinya disebut "waranggana". Waranggana berasal dari kata wara artinya penyanyi, anggana artinya tunggal. Waranggana berarti penyanyi tunggal. Soeroso (1993:12-14) mengungkapkan bahwa seperangkat Gamelan Ageng laras slendro dan laras pelog terdiri atas beberapa macam instrumen yang setiap jenis satuannya disebut ricikan. Ditinjau dari bentuk, bahan, dan cara memainkannya seperangkat Gamelan Ageng dapat digolongkan menjadi jenis ricikan : bentuk tebokan, bentuk bilah, bentuk pencon, bentuk kawatan dan bentuk pipa. Gamelan Jawa terdiri dari instrumen berikut : kendang, bonang, bonang penerus, demung, saron, peking, kenong dan kethuk, slenthem, gender, gong, gambang, rebab, siter, dan suling.

Kesenian mempunyai makna ataupun arti bagi masyarakat pendukungnya. Oleh karena itu bentuk kesenian mempunyai fungsi yang berbeda satu sama lainnya. Soedarsono (1988) mengemukakan, bahwa sebagian besar di Indonesia dalam menyelenggarakan upacara adat wilayahnya menghendaki sajian musik. Misalnya pada upacara kelahiran, pesta panen, perkawinan, kelahiran, dan lain sebagainya (musik sebagai fungsi sosial). Sedangkan untuk puji-pujian khususnya dalam upacara keagamaan kristen dan pengajian dalam islam ( musik sebagai fungsi religius). Baik adat maupun keagamaan mempunyai sifat sakral atau suci, bahkan ada juga yang mengandung kekuatan magis. Ini merupakan satu bukti bahwa musik dapat digunakan sebagai hiburan, dan untuk upacara musik sangat diperlukan atau dibutuhkan dalam suatu bentuk upacara resmi maupun acara tidak resmi. 
Pemaparan diatas memberikan pengertian, bahwa gamelan sebagai bentuk kearifan lokal yang ada di Indonesia memiliki peran penting dalam dinamika perkembangan zaman karena setiap kearifan lokal melalui kesenian tradisional yang ada di Indonesia terdapat nilainilai yang dapat mempengaruhi perilaku seseorang dalam bermasyarakat, sehingga kearifan lokal tersebut perlu dijaga kelestariannya (konservasi).

\section{Metode}

Peneltian ini merupakan jenis penelitian kualitatif yang memanfaatkan pendekatan studi pustaka untuk menganalisis persoalan-persoalan dalam topik penelitian di dalamnya. Musik gamelan merupakan objek material dalam penelitian ini yang didukung dengan objek formal memanfaatkan kajian kearifan lokal dan pendidikan seni di era revolusi industri 4.0.

\section{Hasil dan Pembahasan}

\section{Musik Gamelan}

Pengertian secara umum, gamelan ialah alat musik tradisional Jawa, Bali, dan Sunda yang pada dasarnya menggunakan laras slendro dan pelog. Laras ialah susunan nada yang di dalam satu oktaf intervalnya sudah tertentu. Di dalam karawitan ada dua laras, yaitu : laras slendro dan laras pelog. Soedarsono (1988) mengemukakan, bahwa sebagian besar di Indonesia dalam menyelenggarakan upacara adat wilayahnya menghendaki sajian musik. Misalnya pada upacara kelahiran, pesta panen, perkawinan, kelahiran, dan lain sebagainya (musik sebagai fungsi sosial). Sedangkan untuk puji-pujian khususnya dalam upacara keagamaan kristen dan pengajian dalam islam ( musik sebagai fungsi religius). Baik adat maupun keagamaan mempunyai sifat sakral atau suci, bahkan ada juga yang mengandung kekuatan magis. Ini merupakan satu bukti bahwa musik dapat digunakan sebagai hiburan, dan untuk upacara musik sangat diperlukan atau dibutuhkan dalam suatu bentuk upacara resmi maupun acara tidak resmi.

Dalam penelitian ini, musik gamelan fokusnya yaitu memiliki peran atau fungsi religius, lebih tepatnya penggunaan gamelan dalam ibadah di GBI Ngembak Semarang. Penggunaan gamelan Jawa di GBI Ngembak terangkai dalam sebuah liturgi ibadah Minggu (Kristanto, Sumaryanto, \& Sunarto, 2018). Perkembangan musik di Gereja lebih banyak memanfaatkan band dibandingkan musik tradisional dalam mengiringi liturgi ibadah. Gereja-gereja yang memanfaatkan lagu himn dalam liturgi ibadah minggu cenderung menggunakan keyboard yang memanfaatkan model-model iringan di dalamnya (Kristanto, 2019). Keprihatinan kesenian tradisional yang mulai terabaikan dialami oleh Gereja pada era modern ini. Menurut Bastomi dalam (Hartitom, 2011), berbagai persoalan menyangkut fenomena kebudayaan industri musik populer di dunia yang terjadi pada abad ke-XX, Ki Hajar Dewantara menyatakan bahwa teknologi sangat berpengaruh terhadap perkembangan seni pada umumnya. Hadirnya teknologi komunikasi seperti radio atau televisi dapat mengantarkan pertunjukan wayang maupun bentuk-bentuk kesenian yang lain di rumah-rumah penduduk ataupun melalui media audiovisual. Perkembangan teknologi komunikasi selain membuat orang betah tinggal dirumah juga ternyata menawarkan berbagai macam pertunjukan sehingga membuat daya apresiasi seni masyarakat terhadap pertunjukan wayang semakin menurun. Sehingga perlunya sikap konservatif melalui upaya pelestarian, penelitian, maupun pendokumentasian keseniankesenian tradisional menjadi penting untuk dilakukan (Triyanto Triyanto, Rokhmat, Mujiyono, \& Sugiarto, 2016). 
Pengaruh-pengaruh kebudayaan luar yang begitu deras masuk melalui berbagai media elektronik, juga dapat mempengaruhi minat generasi muda yang cenderung lebih menyukai musik-musik modern daripada kesenian Gamelan Jawa. Fokus pada Gereja Baptis Indonesia di sekitar Semarang dijumpai adanya gamelan Jawa untuk mengisi pujian dalam liturgi ibadah. Ada sesuatu yang menarik perhatian peneliti ketika melihat gamelan Jawa digunakan untuk mengiringi liturgi ibadah di Gereja Baptis Indonesia (GBI) Ngembak Tembalang. Rutinitas ibadah hari Minggu di Gereja Baptis Indonesia (GBI) Ngembak Tembalang menggunakan band sebagai pengiring lagu pujian dalam ibadah. Tetapi pada minggu terakhir dalam setiap bulan di Gereja Baptis Indonesia (GBI) Ngembak Tembalang menggunakan gamelan Jawa untuk mengiringi ibadah di hari Minggu pagi. Permainan musik gamelan di GBI Ngembak Semarang melibatkan beberapa orang didalamnya. Ditemukan fakta bahwa mereka yang terlibat memainkan gamelan merasa senang sekali bisa menjadi bagian dari upaya konservasi kearifan lokal. Nilai-nilai yang dimaknai melalui permainan musik gamelan diantaranya, nilai kebersamaan, nilai tanggungjawab, nilai kepercayaan. Dalam kondisi perasaan sepi, seseorang dapat nglaras atau menyanyikan lagu dengan imajinasi diiringi gamelan dalam lagu-lagu yang dinyanyikan. Penggunaan gamelan juga membawa pengaruh terhadap kualitas spiritual jemaatnya.

\section{Pendidikan Seni berbasis Kearifan Lokal}

Pendidikan memiliki urgensi dalam kebudayaan, diantaranya untuk kemajuan budaya. Pendidikan tidak hanya berorientasi pada pembelajaran di sekolah-sekolah, namun juga berkaitan dengan harga diri dan martabat setiap manusia. Menurut (Jazuli, 2011) dalam dunia pendidikan, konsep pewarisan dapat diidentikkan dengan konsep pembelajaran, transmisi atau transformasi pengetahuan (transfer of knowlwdge) karena pada prinsipnya mencakup proses pengalihan kompetensi dari generasi ke generasi, dalam hal ini dari guru kepada murid. Menurut Liliweri (2015:82), di dalam pendidikan terkandung bentuk pembelajaran pengetahuan, keterampilan, dan kebiasaan sekelompok orang yang diwariskan kepada generasi berikutnya melalui berbagai macam kegiatan, seperti pengajaran, pelatihan, penelitian, hingga belajar sendiri.

Semangat menjadikan manusia sebagai makhluk yang mulia adalah salah satu bentuk spirit ideologi pendidikan seni. Seni hadir sebagai media di dalam dunia pendidikan yang memiliki fungsi untuk menjadikan manusia yang humanis. Sentuhan seni di dalam dunia pendidikan diharapkan mampu menumbuhkan kekuatan sensitifitas perasaan, ekspresi, kreatif dan inovatif. Seni sebagai media di dalam pendidikan mampu membuat siswa lebih mudah menangkap pelajaran-pelajaran yang sebelumnya sulit. Diantaranya mata pelajaran sejarah, jika memanfaatkan seni dalam pembelajarannya maka bentuknya bisa berupa drama musikal, puisi yang didalamnya memuat materi pelajaran sejarah sehingga siswa jadi lebih mudah mengingat dan menangkapnya karena pelajaran sejarah disampaikan lebih menarik dan kreatif.

Seni dalam konteks pendidikan formal memiliki peran penting demi kemajuan budaya bangsa. Seni juga hadir di pendidikan non-formal dan in-formal yang dapat berperan untuk menjaga keseimbangan arus dinamika zaman yang masing-masing zaman membawa dampak terhadap budaya bangsa. Di era revolusi industry 4.0 membawa dampak pada generasi yang ada dan berdampak juga pada kebudayaan bangsa. Era revolusi industri 4.0 memiliki pengaruh positif pada bangsa ini yaitu kemajuan teknologi yang begitu cepat dan pesat mampu meningkatkan efektifitas dan efisiensi di dalam bidang tertentu. Tetapi ada dampak lain diluar pengaruh positif yaitu manusia cenderung memposisikan dirinya sebagai makhluk 
individual. Mereka dapat melakukan aktifitasnya secara mandiri melalui bantuan informasi yang relatif lengkap di media sosialisasi. Upaya menyeimbangkan kondisi zaman di era revolusi industry 4.0 ini seni hadir bersama dengan nilai-nilai kearifan lokalnya yang dapat menjaga sikap manusia dalam kualitas bersosialisasi.

Menurut (T Triyanto, 2009), kearifan lokal adalah pengetahuan atau pandangan, nilainilai, kepercayaan lingkungan terbatas (area lokal) yang diyakini benar membawa manfaat kehidupan sosial. Keberadaannya adalah turun temurun di antara beberapa generasi. Kearifan lokal sebagai bentuk budaya adalah mekanisme budaya yang berfungsi sebagai pedoman untuk mengatur, mengendalikan, dan mengarahkan sikap dan perilaku warga dalam memenuhi kebutuhannya agar memiliki kehidupan yang baik sebagai masyarakat. Kearifan lokal sebagai warisan tradisi yang mengandung pengetahuan, pandangan, nilai-nilai, kepercayaan, dan cara hidup masyarakat diperlukan untuk diwariskan kepada warga negaranya secara turun-temurun. Pada titik ini, pendidikan sebagai lembaga sosial memiliki peran strategis dalam melaksanakan pelestarian kearifan lokal. Sebagai mekanisme budaya, kearifan lokal memiliki beberapa fungsi. Pertama, kearifan lokal menjadi media pengendali bagi perilaku warga. Kedua, menjadi media untuk mempertahankan pengaruh nilai-nilai luar yang tidak tepat. Ketiga, ini berfungsi sebagai strategi adaptasi untuk mengakomodasi pengaruh nilai-nilai budaya dari luar dan mengintegrasikannya dalam budaya asli setempat. Manifestasi kearifan lokal dapat berupa kebiasaan, kebiasaan hidup, gaya atau cara hidup, atau berbagai tradisi budaya, seperti ritual keagamaan, ritual siklus hidup, dan seni tradisional. Dengan kata lain, kearifan lokal sebenarnya adalah perwujudan dari budaya lokal yang diwariskan secara turun-temurun untuk membimbing kehidupan menuju kebaikan bersama.

Di era revolusi industri 4.0 ini, penggunaan musik gamelan di gereja sebagai upaya konservasi nilai-nilai kearifan lokal diharapkan dapat memberikan usulan ide sebagai paradigma baru dalam pendidikan seni. Nilai-nilai yang terkandung di dalamnya yaitu bagaimana seseorang tetap belajar berproses bersama saat bermain gamelan. Nilai kebersamaan hadir didalamnya, di dalam kebersamaan tersebut terdapat interaksi-interaksi yang menumbuhkan sikap toleransi satu dengan yang lain, menumbuhkan sikap empati dan simpati. Upaya konservasi nilai-nilai kearifan lokal tersebut dapat membantu manusia tetap sadar posisinya sebagai makhluk sosial yang saling membutuhkan satu dengan yang lainnya. Menjadi manusia yang memiliki sensitifitas perasaan untuk sesamanya dan lingkungannya. Menjadi manusia yang mampu beradaptasi dan menjaga nilai-nilai kearifan lokal ditengah perubahan-perubahan yang terbentuk dari dinamika perkembangan zaman. Penggunaan musik gamelan di GBI Ngembak terdapat sisi positif lainnya yaitu, dapat diartikan juga sebagai upaya menyeimbangkan antara pengaruh budaya musik barat terhadap budaya lokal. Contoh di atas merupakan bentuk pendidikan seni berbasis kearifan lokal, pendidikan seni di ranah non-formal dan informal telah memiliki kontribusi penting upaya konservasi kearifan lokal. Pendidikan seni berbasis kearifan lokal ini sebagai bentuk upaya konservasi nilai-nilai kearifan lokal ditengah era revolusi industry 4.0. Secara sederhana, pemaparan diatas terkait pendidikan seni berbasis kearifan lokal akan digambarkan dalam bentuk bagan sebagai berikut. 


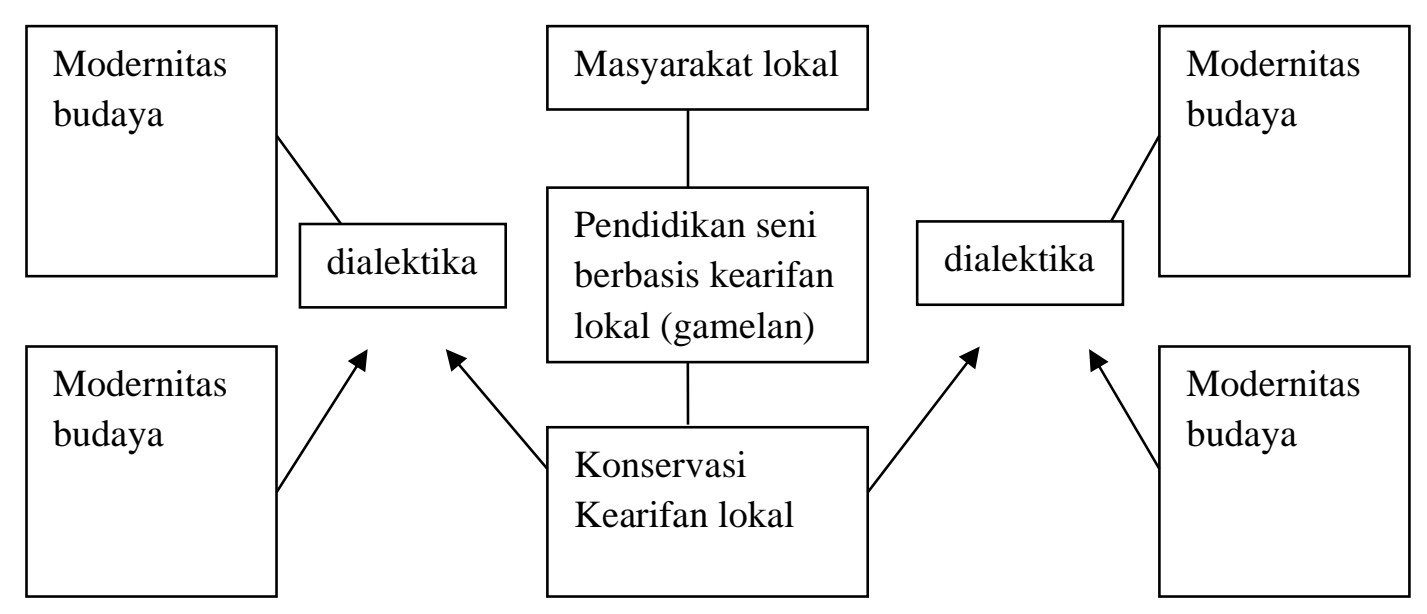

Gambar 1. Alfa Kristanto

Bagan gambar di atas menjelaskan bahwa ditengah modernitas budaya saat ini masyarakat lokal berupaya melakukan konservasi nilai-nilai kearifan lokal yang melibatkan pendidikan seni melalui proses kreatif dan apresiasi. Upaya konservasi kearifan lokal ditengah modernitas budaya saat ini tentunya akan terjadi dialektika demi keseimbangan dinamika budaya di Indonesia.

\section{Kesimpulan}

Dialektika konservasi nilai-nilai kearifan lokal di tengah era revolusi industri 4.0 menjadi isu dan topik yang menarik untuk dibahas. Upaya konservasi nilai-nilai kearifan lokal dapat membantu manusia tetap sadar posisinya sebagai makhluk sosial yang saling membutuhkan satu dengan yang lainnya. Menjadi manusia yang memiliki sensitifitas perasaan untuk sesamanya dan lingkungannya. Menjadi manusia yang mampu beradaptasi dan menjaga nilai-nilai kearifan lokal ditengah perubahan-perubahan yang terbentuk dari dinamika perkembangan zaman. Di era revolusi industri 4.0 membawa dampak pada generasi yang ada dan berdampak juga pada kebudayaan bangsa. Era revolusi industri 4.0 memiliki pengaruh positif pada bangsa ini yaitu kemajuan teknologi yang begitu cepat dan pesat mampu meningkatkan efektifitas dan efisiensi di dalam bidang tertentu. Tetapi ada dampak lain diluar pengaruh positif yaitu manusia cenderung memposisikan dirinya sebagai makhluk individual. Kehadiran konservasi nilai-nilai kearifan lokal mampu menjadi penyeimbang kehidupan di era revolusi industri 4.0 ini.

\section{References}

Andaryani, E. T. (2019). Pengaruh musik dalam meningkatkan mood booster mahasiswa. Musikolastika: Jurnal Pertunjukan dan Pendidikan Musik, 1(2), 109-115. https://doi.org/10.7592/musikolastika.v1i2.31

Aveyard, H. (2014). Doing a literature review in health and social care: A practical guide (Third edition). McGraw-Hill Education, Open University Press.

Booth, A., Sutton, A., \& Papaioannou, D. (2016). Systematic approaches to a successful literature review (Second edition). Sage.

Carayannis, E. G. (Ed.). (2013). Encyclopedia of creativity, invention, innovation and entrepreneurship. Springer New York. https://doi.org/10.1007/978-1-4614-3858-8 
Cook, N. (2018). Music as creative practice: Studies in musical performance as creative practice. Oxford University Press, USA.

de Bruin, L. R. (2019). Expert improvisers' formal, informal and situated influences on learning, motivation and self-efficacy: A qualitative study. Music Education Research, 21(1), 99115. https://doi.org/10.1080/14613808.2018.1516746

Deliège, I. (2006). Musical creativity: Multidisciplinary research in theory and practice (1st ed.). Psychology Press. https://doi.org/10.4324/9780203088111

Euro-net, University of Turku, MCPZ d.o.o., Fab Lab London, \& Erhvervsakademi Sydvest. (2017). InnovatiVET project: Creative problem solving and design thinking. Erasmus+.

Hagata, M., Sitorus, E. R., \& Hapsari, P. D. (2016). Pembelajaran musik kreatif pada siswa [Thesis]. Institut Seni Indonesia Yogyakarta.

Kaufman, J. C., \& Sternberg, R. J. (2006). The international handbook of creativity. Cambridge University Press.

Madore, K. P., Jing, H. G., \& Schacter, D. L. (2016). Divergent creative thinking in young and older adults: Extending the effects of an episodic specificity induction. Memory \& Cognition, 44(6), 974-988. https://doi.org/10.3758/s13421-016-0605-z

McCrae, R. R. (1987). Creativity, divergent thinking, and openness to experience. Journal of Personality and Social Psychology, 52(6), 1258-1265. https://doi.org/10.1037/00223514.52.6.1258

Ritter, S. M., \& Ferguson, S. (2017). Happy creativity: Listening to happy music facilitates divergent thinking. PLOS ONE, 12(9), e0182210. https://doi.org/10.1371/journal.pone.0182210

Runco, M. A. (2007). Encouraging creativity in education. In A.-G. Tan (Ed.), Creativity: A handbook for teachers (pp. vii-ix). World Scientific Publishing Co. Pte. Ltd.

Sternberg, R. J. (2006). Introduction. In J. C. Kaufman \& R. J. Sternberg (Eds.), The international handbook of creativity (pp. 1-9). Cambridge University Press.

Tan, A.-G., Tsubonou, Y., Oie, M., \& Mito, H. (2018). Creativity and music education: A state of art reflection. In Y. Tsubonou, A.-G. Tan, \& M. Oie (Eds.), Creativity in music education (pp. 3-16). Springer Berlin Heidelberg.

Webster, P. R. (2002). Creative thinking in music: Advancing a model. In T. Sullivan \& L. Willingham (Eds.), Creativity and music education (pp. 16-33). The Canadian Music Educators' Association.

Wicaksono, H. Y. (2009). Kreativitas dalam pembelajaran musik. Cakrawalan Pendidikan: Jurnal IImiah Pendidikan, 1, 1-12. https://doi.org/10.21831/cp.v1i1.42 